\title{
Collaborative Safe Escape in Digital Transformation
}

\author{
Ana Inês Oliveira, Pedro Pereira and Javad Jassbi \\ Faculty of Sciences and Technology, Nova University of Lisbon, Caparica, Portugal \\ Uninova Institute, Centre of Technology and Systems (CTS), Portugal \\ aio@uninova.pt,pmrp@.fct.unl.pt,j.jassbi@uninova.pt
}

\begin{abstract}
Hazards are part of human life and every year thousands of people are affectied by different types of natural or human provoked disasters. The evacuation is a crucial part of any rescue plan and there are many procedures and standards to support the process. Nevertheless, traditional methods and procedures need radical changes according to the "4.0" Paradigm. The rate of growth, penetration, and development of technology and more specifically what is known as emerging technologies, changing the norms and routines, and Cyber-physical systems bring intelligent to our life where Hazard Management is no exception. In this paper, a model based on emerging paradigms, called "Collaborative Safe Escape" is proposed for indoor evacuation process. This environment is based on four collaborative networks where evacuee network is a temporary network which would be created in the field when required, while the other are long-term networks with the aim to collaborate in case of hazards to assist the potential victims. The technology and the collaboration between networks create a dynamic connected environment to support the decision of potential victims. In the proposed model, smart buildings including all sensors and devices could provide rich information to be analyzed both by evacuee and rescue team. The Smart Application will keep the people involved in hazards updated by supportive information either by the rescue team or by analyzing the ambient intelligent information. The proposed idea is a future model of Safe Escape Systems in the era of Collaborative Networks and digital transformation.
\end{abstract}

Keywords: Collaborative Safe Escape, Collaborative Networks, Intelligent Buildings, Cyber-Physical Systems, Evacuation Process, Evacuee Decision Process

\section{Introduction}

Dealing with disasters is part of human life since the beginning. In history, many approaches and solutions could be found, and all efforts were simply targeting the life of the impacted people. This is a multidisciplinary subject while most of the works could be categorized into three classes, before, during and after disasters. As this is not a new subject, there is a rich tradition and deep knowledge and experience while emerging technologies and disruptive approaches could help and support the idea in a different way comparing with existing solutions. Regardless of all efforts, nobody could claim that the probability of disasters, either natural or human-provoked, is decreasing while forecasting techniques help us to manage the situations and reduce the consequences but still many people lose their lives or will be affected each year. 
This paper is focused on a very common problem which is safe escape in indoors situation in case of any hazard, with the aim to employ new concepts to assist the involved people in making the best decisions during the time of the escape process. The proposed concept is based on two fundamental pillars: Intelligent connected building, focusing on cyber-physical systems, and collaborative networks. Intelligent connected Building is simply the future of buildings while the building included all things such as furniture and materials could be a "Cyber Physical System" where everything is connected and could collect data, process and share the relevant information. The second key issue is Collaborative Networks which could be considered a key enabler to transit collective behaviour and information to decisive information based on technological solutions. Collaborative Safe Escape using new technologies addressed by IoT, IoP, Bigdata and many other emerging technologies is a new approach to save lives and reduce injuries caused by unpredictable events. The main objective of this paper is to introduce and discuss ae new paradigm of evacuation process based on the latest emerging technologies. This does not mean Smart Building or Connected Devices are new but trying to employ these technologies in a collaborative way and formalize the concept as an innovative operational model to be used in disasters is the goal of this paper. The paper is organized as follow: In the next section, the related trends and challenges are discussed. In section three, the new concept based on four Collaborative Networks is proposed, while section four is dealing with the information flow and decision process of the introduced model. Finally, section five wrap up the final remarks, conclusion and future works.

\section{Trends and Challenges in Digital Safe Escape}

A safe escape planning is very challenging due to the disordered and unorganized situation occurring in a crisis situation. Regrettably, decision makers often have an incomplete picture of hazards and potential escape opportunities. The situation turns out to be more complex due to the fact that people affected are sometimes left alone without any support that could be provided by a rescue team [1]. Without any doubt, decision-making in crises situations needs to be made in the shortest time in order to minimize the potential risk or threat.

Considering the technological evolution and digital transformation that the various contexts of our society have been undergoing, there are certainly several areas of work and research in which new methodologies can be provided in order to support emergency teams and the traditional models of evacuation, naturally aligned with all the inherent legal and social constraints. In the scenario of a panic situation, it is difficult for affected people to determine what are the best decisions in an escape situation. This makes escape planning particularly difficult [3], [4]. On the other hand, this also opens the door to new challenges, that must be tackled, aiming a more efficient escape under a disaster scenario, reducing its consequences (material or human). Therefore, such an environment should include decision systems to enable the choice of the best way to escape, and simulation models to assist in the selection of the fastest and safest escape strategy. These models can use techniques based on agents and artificial intelligence, as is the case of the proposal of the intelligent 
system for disaster management [2]. In Fig. 1 is shown what Authors identified as relevant areas that when combined, perform a collaborative environment, are the key for an effective safe escape.

Several management system proposals are based on the use of intelligent Augmented Reality (AR) models in order to suggest guiding ways which allows rescue teams to quickly reach building occupants [5], for example in case of fire. To this end, a relationship of the physical virtual domain in the building is important.

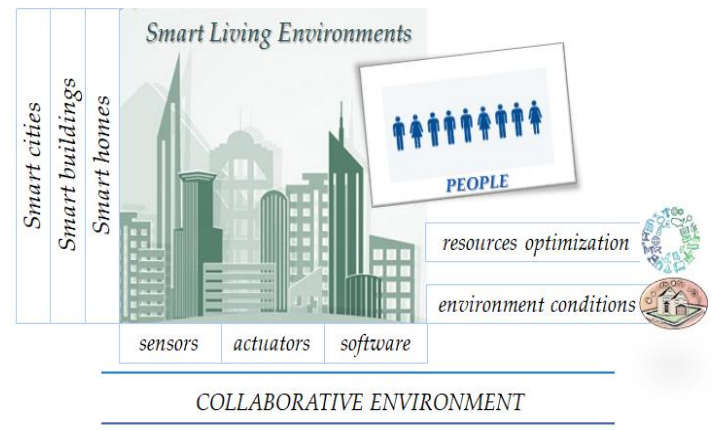

Fig. 1. Relevant contributing areas.

There are some works and prototypes with the aim to perform tasks automatically after emergency situations. An example is the case of active disaster response system (ADRS) [6], which acts automatically after the occurrence of an earthquake. Types of action of this type of system can be for example the opening of doors and windows, cutting water and gas pipes.

To deal with location issues, there are also several works and technological proposals to leverage and streamline solutions for a fast and efficient response in case of disasters [7]. A safe evacuation system by using roads, when a natural disaster occurred, is analyzed and highlighted in [8]. If under such kind of disaster some roads cannot be used, or are blocked, evacuees cannot follow the evacuation procedures by just using default maps after disaster. A safety route guidance system, by using participatory sensing, that uses GPS data and accelerometer data from pedestrians' smartphone, was proposed in [8]. However, the system relies on information that cannot be guaranteed, as is the case of evacuees' smartphone. On the other hand, for indoor issues, there are studies [9] that point out that it is important to know the internal structures and the magnetic fields that buildings can generate, to be able to recognize sources of location. Related to issues of indoor location, there are numerous works that mention vast applications of fingerprint techniques [7], [10], [11]. Moreover, in the context of indoor spaces, WiFi connections are so widespread that internal location based on WiFi has attracted many research efforts. Since fingerprint techniques are considered simple and highly compatible with the hardware that exists in the interior contexts of buildings, the intersection is natural. However, due to unexpected environmental changes, the existing fingerprint location algorithms may not work as expected. There is research suggesting that it is possible, through offline mechanisms and voting systems, to improve the accuracy of the location, when effectively compared with the existing fingerprint location algorithms [10]. Other 
works suggests algorithms that improve received signal strength indication (RSSI) [12][13], or use Bluetooth Low Energy positioning methods based on the fingerprint technique, according to $\mathrm{Wi}-\mathrm{Fi}$ location techniques [14]. These localization mechanisms are used in various contexts, such as location (non-evasive) of the elderly [14], nonetheless, they can be used or adapted for use in emergency situations or in disruptive environments.

In [15] is reported a firefighting scenario, affirming that most fire departments make judgments during fire rescue operations based on previous acquired knowledge, without a path-planning system that is capable of real-time information. An evacuation architecture supported by multi-agents that collects information from evacuees and from sensors in a real-time basis, aims to provide the safest and fastest escape route for different groups inside the same building, is propose in [16].

Several works on Crowd Behaviour Analysis Technology for Disaster Management $[17,18,19,20]$ have been performed and are useful in this type of situations where an inherent characteristic is the behavioural analysis of the occupants of spaces to be evacuated. In this type of situations, however, there should be a collaborative support so that the various entities related to the situation that is occurring can intervene. As so, with a support that makes these entities more prepared to collaborate in cases of incidents, their intervention can become faster and more effective. There are studies to create working models for complex emergency situations, with support in multi-risk analysis [21] to explore different courses of action, using a Cross Impact Analysis and Interpretative Structural Modeling (CIAISM) [22,23] methodology to support group collaboration. In order to select collaboration partners and tasks during the formation of the collaborative crisis response network, it is necessary that various requirements are considered and parameterized [24]. There are projects, such as the SoKNOS project [25] to develop and test required concepts to support government, private and non-profit organizations involved in public security issues that include Human-Computer Interaction (HCI). It can also be considered systems that can help people, especially those with sensory impairments (visual or hearing) [26].

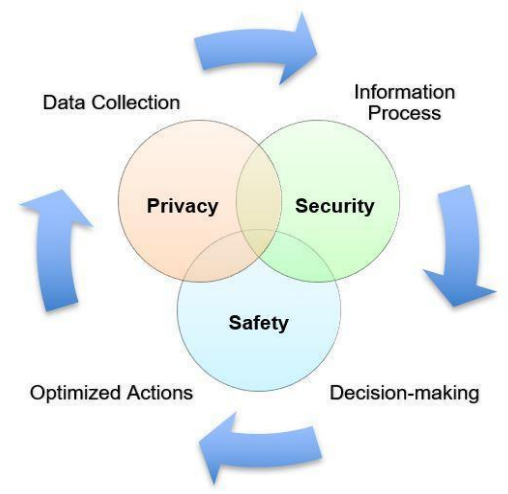

Fig. 2. Structure diagram for a Safe Escape.

Empowering such a Safe Escape system requires a cyber-physical infrastructure that combines new software platforms with very challenging requirements related 
with safety, security and privacy. Additionally, the system must be able to collect, manage and process a massive amount of data. Today's standard is the use of a cloud platform in which most data is stored, and several real-time applications are continuously running, although issues regarding data security and data protection are still quite demanding. At this point it is worth to highlight that from the Authors point of view a Safe Escape relies in a "system" that comprises different stages: data collection, processing, decision-making and actions; as depicted in Fig. 2.

A proper understanding of both "cyber" and "physical" components that considers the importance of privacy, security and safety, allied with the diverse nature of data collection, and consequently the actuation procedures that should occur, is required. One of the main challenges that must be tackled is the integration of a widely sort of distributed devices into a common framework. For instance, the different type of sensors, such as cameras, temperature, smoke, crack detection, among many others, that could be installed in a certain building, must be able to communicate/interact with each other, as well as with building occupants through smartphones, tablets, laptops and, of course, servers. From Authors' perspective, several reported works are too focused in proposing a solution at a physical layer level, sometimes forgetting the social and collaborative behaviour of evacuees. Thus, it is our understanding that a safe escape should consider: 1) aggregate data from different sources (sensors, historical data, among others), 2) new but also mature technologies in order to increase the system resilience, 3) interaction between different players, as networks, for instance building managers, and local teams, rescue teams including firefighters, police, etc., creating a collaborative ecosystem, and 4) cooperation / collaboration between cyber physical systems and smart social environment, and dynamic decisionmaking platforms.

\section{Towards a Conceptual Model for Collaborative Escape}

In order to achieve an environment to become more effective for all parties involved in the escape process, a solution based on the collaboration of all stakeholders and making use of an appropriated infrastructure is proposed. In this direction, it is aimed to achieve an environment that creates disaster awareness and support in situations of need, based on the combination of cyber-physical systems and collaborative networks paradigms (Fig. 3). On one hand, the Collaborative Networks [27] paradigm can provide appropriate mechanisms, adding value to the logical collaboration between rescue entities, but also between all other parties involved, including the local spaces from where the escape needs to take place, to the users of the spaces themselves. On the other hand, the cyber-physical systems can deal with the integration of computation, networking and physical processes.

In this context, it is possible to foresee distinct types of network, namely: rescue network, local network, evacuees network, and a network of cyber-physical systems existing in the corresponding spaces. A brief description of these networks is included in Table 1. 


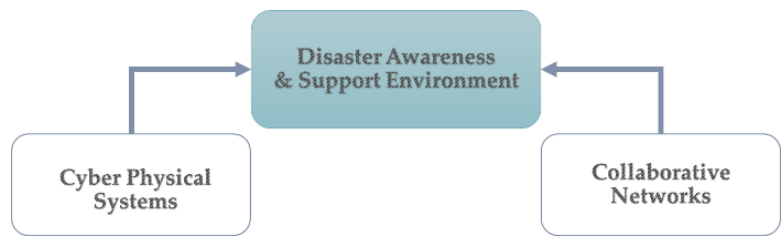

Fig. 3. Disaster awareness and support environment bases.

Fig. 4 shows the concept of the proposed model and the flow of information among the four networks in Safe Escape. There is an evident combination of characteristics among these networks, starting from their duration, that can be long or short term, to their membership, that can include or not members from other networks. Therefore, to have a clearer understanding of these networks, tables below include their characterization using the ARCON Framework [28].

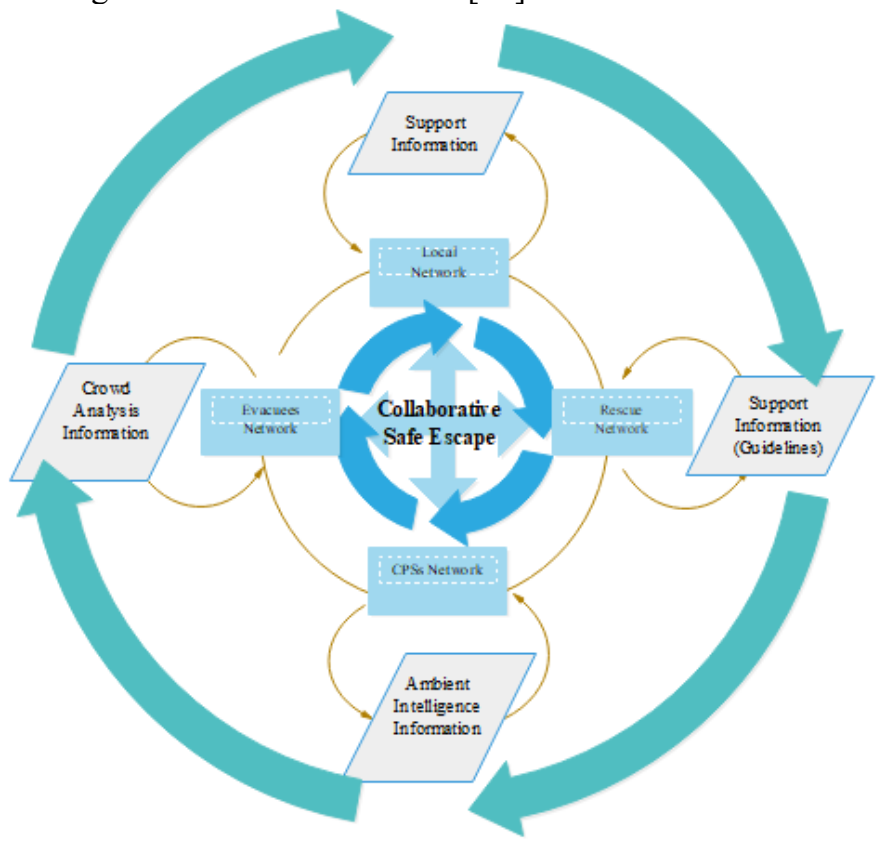

Fig. 4. Information flow in Safe Escape.

Being the focus, a general representation of concepts and related relationships, the ARCON's Model Intent general representation layer [29] is used, converging on the description of the main elements of the endogenous and exogenous perspectives (namely on the structural and componential endogenous perspective and support and societal exogenous perspective). This characterization considers the operation stage of the lifecycle of the identified networks. The other stages, namely formation, dissolution and evolution are out of scope of the work presented in this paper and will be characterized in further works. 
Table 1. Description of involved collaborative networks.

\begin{tabular}{ll}
\hline Network & Description \\
\hline rescue network & $\begin{array}{l}\text { Long-term alliance that involves different types of rescue entities, that } \\
\text { must collaborate in a disaster situation. }\end{array}$ \\
\hline local network & $\begin{array}{l}\text { Long-term strategic network to provide support to local places or spaces } \\
\text { in case of disaster. Places can differ in their nature, from a shopping } \\
\text { center, to a hotel or any other indoor environment. This network includes } \\
\text { the owner of the space, the managers, employees, etc. }\end{array}$ \\
\hline evacuees network & $\begin{array}{l}\text { Temporary virtual organization involved in the rescue process and } \\
\text { involving the occupants of the corresponding indoor contexts. The } \\
\text { created consortium typically dissolves after the resolution of the hazard. }\end{array}$ \\
\hline cyber-physical & $\begin{array}{l}\text { Network of intelligent physical and software entities that are present in } \\
\text { the local places. }\end{array}$ \\
\hline
\end{tabular}

Table 2. Characterization of rescue network.

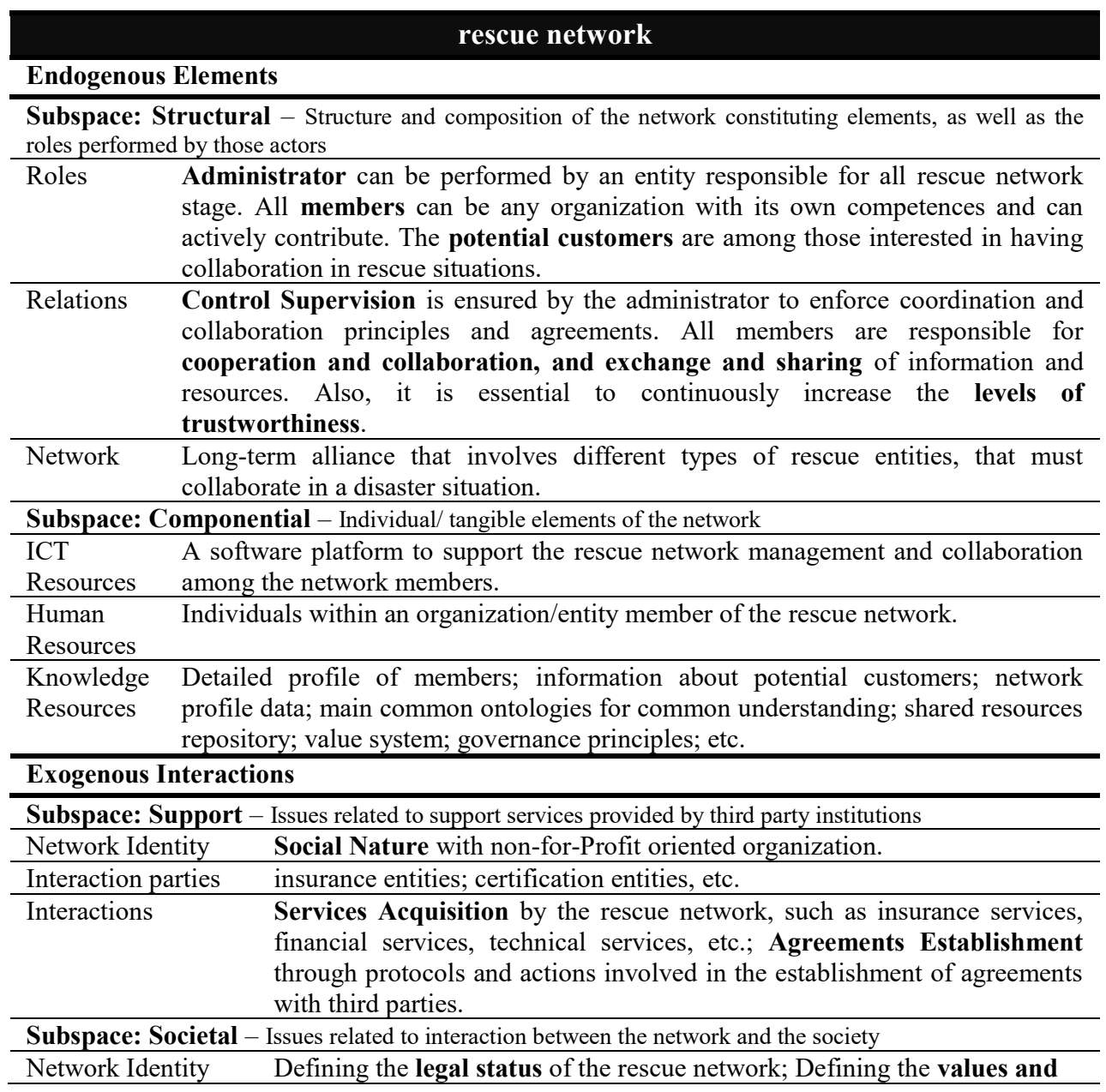




\begin{tabular}{ll}
\hline & principles that characterize the identity the rescue network. \\
\hline Interaction parties & $\begin{array}{l}\text { Identifying the governmental organizations and associations that interact } \\
\text { with the rescue network; Identifying the public or private entities } \\
\text { (Regulatory Bodies) that issue regulations and standards. }\end{array}$ \\
\hline Interactions & $\begin{array}{l}\text { Political Relations: defining with which parties there are political } \\
\text { interactions established; Information Transfer: defining the information } \\
\text { that is transferred between the rescue network and each third party. }\end{array}$ \\
\hline
\end{tabular}

Table 3. Characterization of local network.

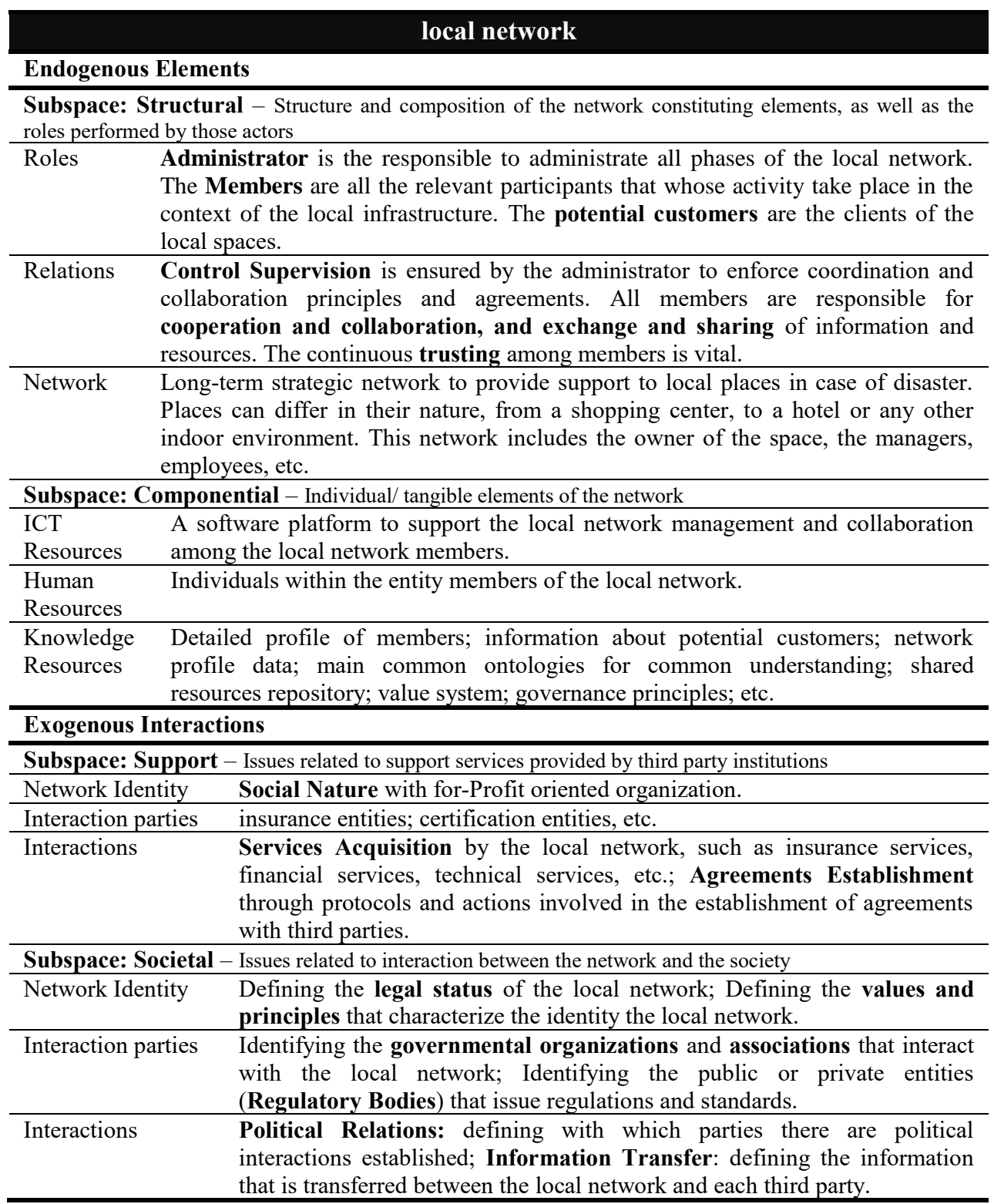


Table 4. Characterization of evacuees network.

\begin{tabular}{|c|c|}
\hline & Evacuees net \\
\hline an & lements \\
\hline $\begin{array}{l}\text { Subspace: } \\
\text { roles perform }\end{array}$ & $\begin{array}{l}\text { Structural }- \text { Structure and composition of the network constituting elements, as well as the } \\
\text { ed by those actors }\end{array}$ \\
\hline Roles & $\begin{array}{l}\text { Planner is responsible for the formation of the evacuees network, typically some } \\
\text { member of local network; the Coordinator is responsible for the coordination of the } \\
\text { evacuees network during its duration; the Partner represents all the involved actors } \\
\text { within the collaborative space of evacuees. }\end{array}$ \\
\hline Relations & $\begin{array}{l}\text { Control Supervision under the responsibility of the Coordinator; Collaboration, } \\
\text { Exchanging and Sharing between all partners; The continuous trusting among } \\
\text { members is vital. }\end{array}$ \\
\hline Network & $\begin{array}{l}\text { Temporary virtual organization involved in the rescue process and involving the } \\
\text { occupants of the corresponding indoor contexts. The created consortium typically } \\
\text { dissolves after the resolution of the hazard. }\end{array}$ \\
\hline Subspace: & Componential - Individual/ tangible elements of the network \\
\hline $\begin{array}{l}\text { ICT } \\
\text { Resources }\end{array}$ & $\begin{array}{l}\text { A software platform to support the formation and the management of the evacuees } \\
\text { network. This platform is typically part of the platform used by the local network. }\end{array}$ \\
\hline $\begin{array}{l}\text { Human } \\
\text { Resources }\end{array}$ & $\begin{array}{l}\text { Different partners can be assigned to specific tasks of the evacuees network; } \\
\text { Specific individuals can contribute. }\end{array}$ \\
\hline $\begin{array}{l}\text { Knowledge } \\
\text { Resources }\end{array}$ & $\begin{array}{l}\text { Local network Shared Resources; Templates with models or reference documents } \\
\text { to be instantiated for a specific use case; Main common ontologies used to } \\
\text { facilitate the common understanding among the network partners; etc. }\end{array}$ \\
\hline
\end{tabular}

Table 5. Characterization of cyber-physical systems network.

\begin{tabular}{|c|c|}
\hline \multicolumn{2}{|c|}{$\begin{array}{l}\text { cyber-physical systems network } \\
\end{array}$} \\
\hline \multicolumn{2}{|c|}{$\begin{array}{l}\text { Subspace: Structural - Structure and composition of the network constituting elements, as well as the } \\
\text { roles performed by those actors }\end{array}$} \\
\hline Roles & \multirow{2}{*}{$\begin{array}{l}\text { Due to the different nature of this network, namely its partners, the defined roles } \\
\text { and corresponding relations have to be defined and configured according to the } \\
\text { nature of the corresponding environment context. }\end{array}$} \\
\hline Relations & \\
\hline Network & $\begin{array}{l}\text { Network of intelligent physical and software entities that are present in the local } \\
\text { places. }\end{array}$ \\
\hline \multicolumn{2}{|c|}{ Subspace: Componential - Individual/ tangible elements of the network } \\
\hline $\begin{array}{l}\text { ICT } \\
\text { Resources }\end{array}$ & $\begin{array}{l}\text { A software platform to support the formation and the management all the devices } \\
\text { that can be part of the cyber-physical systems network. This platform is typically } \\
\text { part of the platform used by the local network or by the rescue network. }\end{array}$ \\
\hline $\begin{array}{l}\text { Human } \\
\text { Resources }\end{array}$ & N/A \\
\hline $\begin{array}{l}\text { Knowledge } \\
\text { Resources }\end{array}$ & 1 network Shared Resources; relational and no relational databases, etc. \\
\hline
\end{tabular}

Needless to say that the core communication channel in Collaborative Safe Network is based on technology and there is always the risk of collapsing infrastructure which causes all centralized systems to stop working. That's why it is important to make sure the system is being developed based on a modular approach and with peer to peer strategy. This can help in case of degradation and collapse of 
technological infrastructure to continue the support of the evacuees. Most people could use their smartphones and if it could not be connected to any central network, they could connect to each other and exchange information to support the decisions for a safe escape. Also, using temporary technological solutions such as mobile autonomous robots that could help to bring back temporary network or connect to smartphones, analyze the information and exchange messages as alternative solutions. Moreover, it is important to have different protocols and strategies to make sure collaborative networks could continue working on different occasions.

\section{Dynamic Decision Model in Collaborative Escape}

The main idea of the proposed model in this paper is based on the simple fact that the most important issue in the time of disasters is to make the right decisions at the right time. This means both efficiency and effectiveness are important and time is crucial. Not only because each second could save a life but due to the dynamism of the problem and rapid changes which could happen. For example, if the static maps show the exit path and even it was the best solution in the initial stage of the hazard, due to many factors such as the effect of infrastructure or behavior of the people, it could change from time to time. Collaborative Escape is a solution to keep the evacuees updated online and help them for the best decisions.

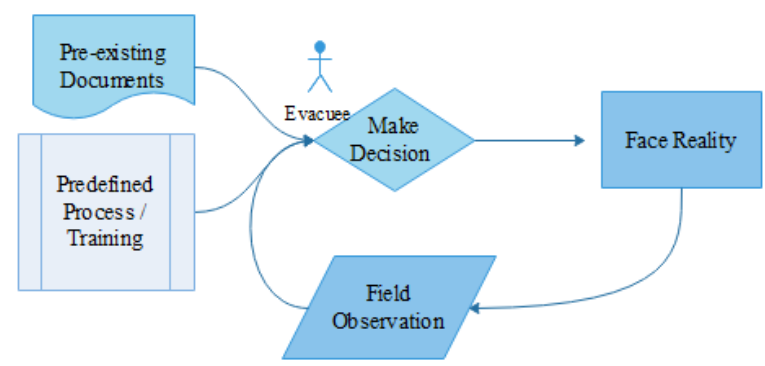

Fig. 5. Simple decision-making process of evacuee.

Fig. 5 and Fig. 6 compare the decision making process of evacuees in the current situation and in the ideal situation which we call "Collaborative Safe Escape". As it could be seen, in the classic model, in the best scenario, the potential victim has the regular information, know the process and could follow the pre-existing signs and guidelines while the field observation is the only way to receive feedback. This means $\mathrm{s} /$ he could change his/her strategy only when could feel something is wrong which could be sometimes too late. In the proposing model, not only the smart Building as a CPS, but the cumulative behaviour of the evacuee and the information from the local network could help the rescue team and the evacuee to manage the situation. All information, considering different types of data sources, would be analyzed and different scenarios would be simulated to give the best and last guidelines to the people who are trying to escape from danger. As illustrated in Fig. 6, a variety of information and data sources and the technologies could help the evacuees to make a better decision and avoid common pitfalls such as following wrong dominant 
behaviour or failing by running to trap. There is no doubt that creating a Safe Escape Collaborative Network is not just technology, but a conceptual model based on CNs paradigm to employ emerging technologies in an efficient and effective way. The goal is to develop a system which could be active in case of any disaster. Smart Building as a CPSs and AI to analyze and simulate the crowd behaviour and Big data to enhance the level of services which could be provided in evacuation process in disasters to save more lives and reduce the negative impact of hazards.

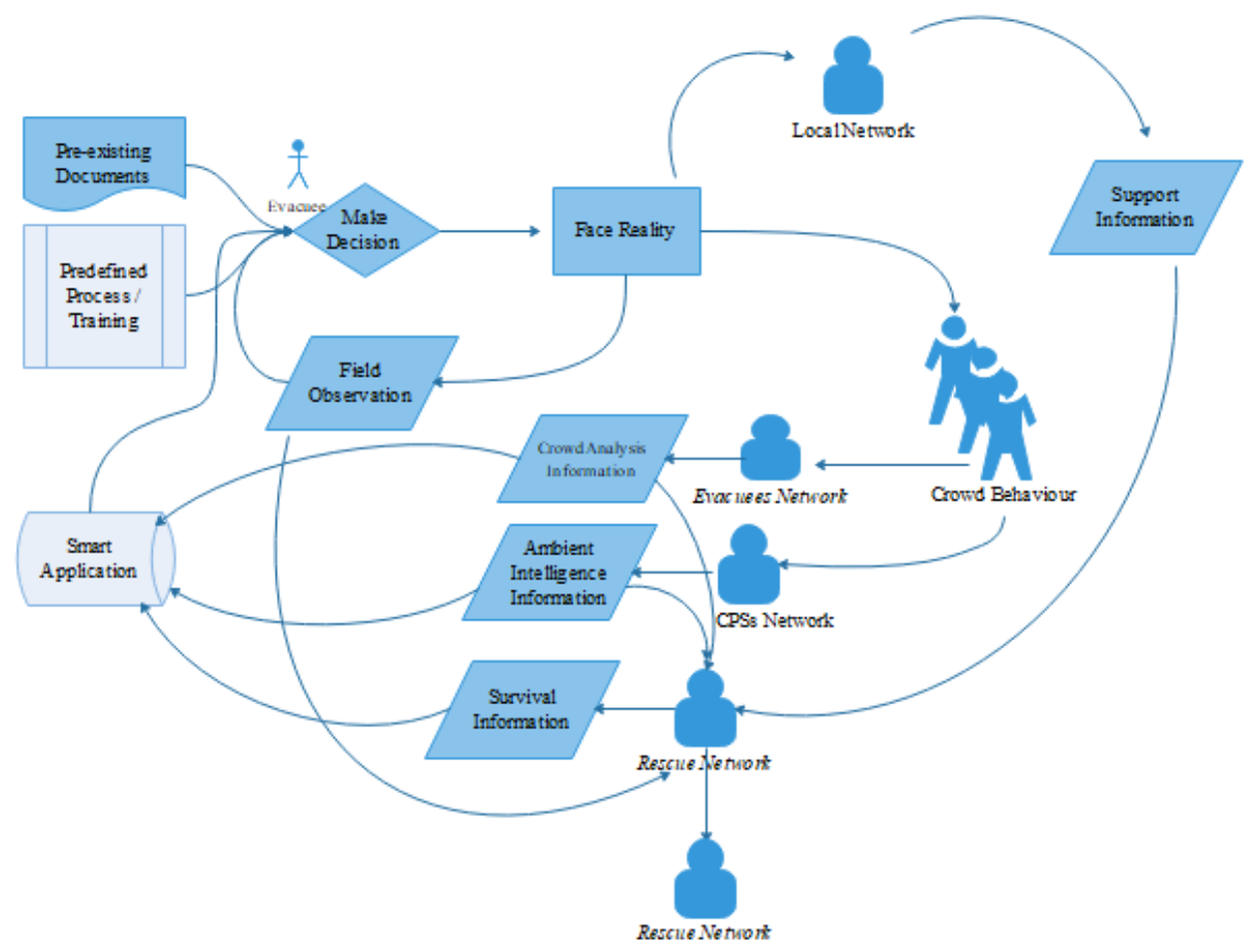

Fig. 6. Decision making process of evacuee in Safe Escape.

\section{Final Remarks}

Dealing with disasters is part of human life, nonetheless, several approaches and solutions have been proposed to minimize its impacts on citizens daily life. As shown, this is a multidisciplinary topic, thus can only be handled by multidisciplinary teams. In this work, Authors tried to show that smart buildings, which includes not only all things (equipment or materials) inside it, but also people, can be seen as a CPS, where everything is connected. The information management system should be able to collect data from different sources, process it and share significant information. Additionally, in a higher layer, a collaborative network should be considered as a key enabler in order to translate collective behaviour and information into decisive 
information thanks to technological solutions. Collaborative Safe Escape using new technologies is a new approach, that must be tackled, aiming a more efficient escape, reducing its consequences (material or human) due to unpredictable events. The characterization of the different networks presented in section 3, shall be further detailed including the specification of the functional and behavioural, and market and constituency dimensions of the endogenous and exogenous perspectives, respectively, in the Model Intent general representation layer of the ARCON reference model. Furthermore, in this work only the operation stage of the networks is characterized, thus the complete lifecycle shall be characterized in latter works. Finally, in section 4, the proposed model is discussed from the perspective of the decision-making process while the evacuee, as a potential victim, is considered as a decision maker. The combination of data sources from the networks and technologies could support the decision process and in a smart online platform, the evacuee could receive supportive information to find the best personalized solution to escape from the danger. Being this work still ongoing, it is expected that its content can provide decision-makers, as well as building owners, with supportive guidelines and directions for achieving effective and efficient safe escape.

In conclusion, this paper proposes a conceptual model which could be a revolutionary strategy to change the evacuation process in disasters. However, further research is required in areas which can be considered as interesting directions, such as: challenge of communication between the evacuees and the collaborative networks as peer to peer system; distributed computing system to keep the system running in case of failure of central infrastructure; modeling the processes and procedure in CNs and between $\mathrm{CNs}$ to understand the needs and to improve the efficiency according to the goals in the evacuation process; simulation of the evacuation process using the proposed model to see the weaknesses, disadvantages in practice and try to find solutions to improve it; blockchain technology to improve communications security in order to improve cybersecurity, avoiding cyberattacks aiming to create panic due to false disaster alert; Artificial Intelligence and Machine Learning can be used to improve facial recognition algorithms, which can be used to identify evacuees; etc.

Acknowledgments. This work was funded in part by the Portuguese FCT Strategic program UID/EEA/00066/2019.

\section{References}

1. Goodwin, M., Granmo, OC., Radianti, J., Sarshar, P., Glimsdal, S.: Ant Colony Optimisation for Planning Safe Escape Routes. In: Ali M., Bosse T., Hindriks K.V., Hoogendoorn M., Jonker C.M., Treur J. (eds) Recent Trends in Applied Artificial Intelligence. IEA/AIE 2013. Lecture Notes in Computer Science, vol 7906. Springer, Berlin, Heidelberg (2013).

2. Mirahadi F., McCabe B, Shahi A.: Smart Disaster Management System for Tall Buildings. In: Canadian Society for Civil Engineering (CSCE) Annual Conference (2017).

3. Li, Q., Rus, D.: Navigation protocols in sensor networks. ACM Transactions on Sensor Networks (TOSN) 1(1), pp. 3-35 (2005). 
4. Li, Q., De Rosa, M., Rus, D.: Distributed algorithms for guiding navigation across a sensor network. In: Proceedings of the 9th Annual International Conference on Mobile Computing and Networking, pp. 313-325. ACM (2003).

5. Park, S.; Park, S.H.; Park, L.W.; Park, S.; Lee, S.; Lee, T.; Lee, S.H.; Jang, H.; Kim, S.M.; Chang, H.; Park, S. Design and Implementation of a Smart IoT Based Building and Town Disaster Management System in Smart City Infrastructure. In: Applied Sciences. 8(11), pp. 1-27 (2018).

6. Lin, C., Chu, E.T., Ku, L., Liu, J.W.: Active Disaster Response System for a Smart Building. In: Sensors, 14, pp. 17451-17470 (2014).

7. Wenge, T., Chew, M. T., Alam, F., Gupta, G. S.: Implementation of a Visible Light based Indoor Localization System. In: IEEE Sensors Applications Symposium (SAS) (2018).

8. Ikeda Y., Inoue M.: An Evacuation Route Planning for Safety Route Guidance System after Natural Disaster Using Multi-Objective Genetic Algorithm. In: Procedia Computer Science (96), pp. 1323-1331 (2016)

9. Kwak, M., Park, Y., Kim, J., Han, J., Kwon, T.: An Energy-efficient and Lightweight Indoor Localization System for Internet-of-Things (IoT) Environments. In: Proceedings ofACM Interactive Mobile. Wearable Ubiquitous Technology, 2(1), pp.1-28 (2018).

10. Luo, J., Yin, X., Zheng, Y., Wang, C.: Secure Indoor Localization Based on Extracting Trusted Fingerprint. In: Sensors, 18(2), pp. 1-23 (2018).

11. Félix, G., Siller, M., Álvarez, E. N.: A fingerprinting indoor localization algorithm based deep learning. In: Eighth International Conference on Ubiquitous and Future Networks (ICUFN), pp. 1006-1011 (2016).

12. Xue, W., Qiu, W., Hua, X., Yu, K.: Improved Wi-Fi RSSI Measurement for Indoor Localization. In: IEEE Sensors Journal, vol. 17(7), pp. 2224-2230 (2017).

13. Xue, W., Hua, X., Li, Q., Yu, K., Qiu, W., Zhou, B., Cheng, K.: A New Weighted Algorithm Based on the Uneven Spatial Resolution of RSSI for Indoor Localization. In: IEEE Access, 6, pp. 26588-26595 (2018).

14. Longo, A., Rizzi, M., Amendolare, D., Stanisci, S., Russo, R., Cice, G., D’Aloia, M.: Localization and monitoring system based on BLE fingerprint method. In: Proceedings of the Workshop on Artificial Intelligence with Application in Health (WAIAH), 1982, pp. 25-32 (2017).

15. Chou, J.-S.; Cheng, M.-Y.; Hsieh, Y.-M.; Yang, I.-T. and Hsu, H.-T.: Optimal path planning in real time for dynamic building fire rescue operations using wireless sensors and visual guidance. In: Journal of Automation in Construction (99), pp.1-17 (2019).

16. Khalid Q., Fernández A., Lujak M., Doniec A.: A Group Evacuation Method for Smart Buildings. In: Camarinha-Matos L., Almeida R., Oliveira J. (eds) Technological Innovation for Industry and Service Systems. DoCEIS 2019. IFIP Advances in Information and Communication Technology, 553, pp. 206-213, Springer, Cham (2019).

17. Integrating Physical and Cyber Security for Safer Cities (A Frost \& Sullivan White Paper), https://dkf1ato8y5dsg.cloudfront.net/uploads/5/82/necintegratingphysicalandcybersecurityforsafercities.pdf

18. Taking of with Digital Identity - How a single ID will transform air travel, https://dkf1ato8y5dsg.cloudfront.net/uploads/5/82/2.pdf

19. Securing Experiences via Digital Identity (A Frost \& Sullivan Executive Briefing Paper), https://dkf1ato8y5dsg.cloudfront.net/uploads/5/82/nec-securingexperiencesexecutivevriefingpaper.pdf

20. Ensuring Digital Safety with Robust Cyber Security (NEC public safety white paper), https://dkf1 ato8y5dsg.cloudfront.net/uploads/5/82/nec-ensuring-digital-safety.pdf 
21. Bañuls, V. A., Turoff, M., Hiltz, S. R.: Collaborative scenario modeling in emergency management through cross-impact. In: Technological Forecasting and Social Change, 80(9), pp. 1756-1774 (2013).

22. Turoff, M., Bañuls, V. A., Plotnick, L., Hiltz, S. R., Huerga, M. R.: Collaborative Evolution of a Dynamic Scenario Model for the Interaction of Critical Infrastructures. In: Proceedings of the International Conference on Information Systems for Crisis Response and Management (ISCRAM) (2015).

23. Turoff, M., Bañuls, V. A., Plotnick, L., Hiltz, S. R., Huerga, M. R.: A collaborative dynamic scenario model for the interaction of critical infrastructures. In: Futures, 84(A), pp. 23-42, Elsevier (2016).

24. Bodinab, Ö., Nohrstedtc, D.: Formation and performance of collaborative disaster management networks: Evidence from a Swedish wildfire response, In: Global Environmental Change, 41, pp. 183-194, Elsevier (2016).

25. Flentge, F., Weber, S.G., Behring, A., Ziegert, T.: Designing Context-Aware HCI for Collaborative Emergency Management. In: International Workshop on HCI for Emergencies (2008).

26. Baudoin, G., Venard, O.: Information, communication and localization environment for travelers with sensory disabilities in public transports. In: 5th International ICST Conference on Communications and Networking, pp. 1-7 (2010)

27. Camarinha-Matos, L. M., \& Afsarmanesh, H. (2005). Collaborative networks: a new scientific discipline. Journal of Intelligent Manufacturing, 16(4-5), 439-452.(2005).

28. Camarinha-Matos, L. M., Afsarmanesh, H., Ermilova, E., Ferrada, F., Klen, A., \& Jarimo, T.: ARCON reference models for collaborative networks. Collaborative Networks: Reference Modeling, 83-112. (2008).

29. Camarinha-Matos, L. M., \& Afsarmanesh, H. (Eds.): Collaborative networks: Reference modeling. Springer Science \& Business Media.(2008). 